\title{
Jurisdição Processual e Democracia: Advento da Audiência de Conciliação e de Mediação, Efetivação dos Meios Equivalentes e Acesso À JUSTIÇA
}

\author{
Daniel Mota Gutierrez* \\ Jânio Pereira da Cunha**
}

\begin{abstract}
Considerações iniciais. 1 Aspectos gerais sobre conciliação e mediação. 2 Jurisdição processual democrática : fundamentos. 3 . Audiência de conciliação e de medidaçao no novo código de processo civil ( NCPC): inovações e acesso à justiça. 3.1 Considerações gerais de cunho comparativo entre a audiência preliminar (art. 331, CPC/73) e a audiência de conciliação ou de mediação (art. 334, NCPC). 3.2 Dos requisitos básicos para a designação da audiência de conciliação e de mediação. 3.3 Da atuação necessária do conciliador ou do mediador. $3.4 \mathrm{~A}$ previsão de prazos mínimos de antecedência para a designação de data para a audiência e para a citação do réu, bem como de intervalo mínimo entre as audiências. 3.5 Da novidade da audiência por meio eletrônico e a sanção pelo não comparecimento à audiência. 3.6 Inovações legislativas relativas à audiência de conciliação e de mediação do NCPC: avanço ou retrocesso à luz do conceito contemporâneo de jurisdição e de acesso à justiça. Considerações finais. Referencias.
\end{abstract}

\section{RESUMO}

Versa sobre os meios consensuais de resolução de conflitos, especificamente a conciliação e a mediação. Investiga-se, de início, se tais meios alternativos à jurisdição tradicional se compatibilizam com os valores democráticos, de tal sorte a viabilizar a participação popular dos litigantes na interpretação e aplicação do Direito. Discute-se, depois, acerca da fisionomia normativa da conciliação e da mediação no sistema jurídico brasileiro, destacando as principais inovações trazidas pelo novo Código de Processo Civil (NCPC), com relação à introdução da audiência de conciliação e de mediação. Perquire-se, empós, se as alterações normativas procedidas nos institutos sobreditos representam avanço ou retrocesso no ideal de acesso à justiça. Conclui-se que a conciliação e a mediação constituem instrumentos que podem proporcionar a participação direta dos cidadãos na administração da justiça e que a reformulação implementada pelo NCPC nesses procedimentos

* Professor do Curso de Direito do Centro Universitário Christus (Unichritus). Doutor em Direito Processual Civil pela PUC/SP. E-mail: dgutierrez@uol.com.br.

** Professor do Curso de Direito do Centro Universitário Christus (Unichritus). Professor Auxiliar 3 do Curso de Direito da Universidade de Fortaleza (Unifor). Doutor em Direito Constitucional pela Unifor. E-mail: janiopcunha@ig.com.br. 
judiciais aproxima o sistema processual civil pátrio dos conceitos contemporâneos de jurisdição democrática e acesso à justiça.

Palavras-chave: Acesso à Justiça. Conciliação. Mediação. Democracia.

\section{CONSIDERAÇÕES INICIAIS}

Há uma crise no sistema brasileiro de Justiça. A cada dia cresce a insatisfação com o desempenho das instituições jurídicas ${ }^{1}$, principalmente após promulgada a Constituição de 1988, quando nela foi positivado um extenso rol de garantias e direitos fundamentais que potencializou a demanda histórica reprimida por serviços judiciais com vistas à concretização dos princípios e valores protetivos da pessoa humana.

Na verdade, o problema da prestação jurisdicional decorre de inúmeras causas. A doutrina especializada indica como sendo as principais o elevado número de processos (inflação processual) ${ }^{2}$ o custo e a morosidade na tramitação dos feitos, a burocratização dos procedimentos, o complicado tecnicismo, a carência e a baixa qualidade de recursos humanos, a dificuldade de acesso dos hipossuficientes e a efetividade relativa das decisões, entre outros fatores de ordem institucional, normativa, econômica e cultural. ${ }^{3}$

É certo também que a crise de administração da Justiça não é exclusiva do Brasil. Trata-se, apesar das peculiaridades de cada experiência estatal, de um fenômeno de amplitude mundial ${ }^{4}$, inclusive com problemas comuns, como a ineficiência e a inadequação dos instrumentos processuais tradicionais para lidar satisfatoriamente com o número, a diversidade e a complexidade dos conflitos em sociedades hipercomplexas como as atuais. ${ }^{5}$

Desenvolvem-se, no Brasil, em razão desse complicado e grave estado de coisas, acompanhando, diga-se de passagem, a tendência global, formas alternativas de resolução de conflitos de interesses, objetivando racionalizar a administração da Justiça, de tal sorte a efetivar, em grande medida, o fim ideal e último da jurisdição: a pacificação social. Entre os meios alternativos à jurisdição tradicional ${ }^{6}$, dois serão o objeto deste artigo: a conciliação e a mediação. ${ }^{7}$

A escolha aqui desses expedientes opcionais não ocorreu de modo aleatório, mas em razão de serem esses os dois principais meios de composição consensual de choque de interesses, bem como em virtude das recentes inovações normativas pelas quais transitaram tais procedimentos no ordenamento jurídico brasileiro.

Feitas tais considerações iniciais, advirta-se do fato de que o objetivo deste estudo não é inovar a literatura especializada sobre a temática das soluções não propriamente jurisdicionais dos conflitos, mas, no primeiro momento, traçar a conceituação, as características, os princípios informativos e a finalidade geral e específica dos institutos da conciliação e da mediação. Em segundo lugar, impende discorrer sobre os fundamentos democráticos e constitucionais de tais 
meios alternativos de composição de lides, destacando a ideia de que ambos constituem técnicas fundamentais para se estruturar uma jurisdição processual democrática e participativa.

Considerando-se o fato de que, em março de 2016, entrará em vigor o Novo Código de Processo Civil brasileiro (NCPC), a terceira parte deste trabalho analisará as principais alterações na sistemática do processo civil, no concernente à introdução da audiência de conciliação ou de mediação pelo NCPC, notadamente em cotejo com o regime da audiência preliminar do CPC/73. Destaque-se que o estudo é tecido com base em problematizações, com o objetivo de auxiliar os operadores do direito na solução de questões práticas ou dúvidas do cotidiano forense, que já existem ou que venham a surgir com o advento da aguardada vigência do instituto.

Ademais, também é escopo deste estudo efetuar uma reflexão crítica sobre o que tais mudanças representam sob o ponto de vista do acesso à justiça e da efetividade dos procedimentos conciliadores e mediadores, na qualidade de meios equivalentes de resolução de conflitos, bem assim da aderência das referidas alterações à Constituição Federal. Especificamente, a última parte discutirá se as inovações legislativas, no pertinente à audiência de conciliação e de mediação do NCPC, significam avanço ou retrocesso no tocante a estruturar e aperfeiçoar uma jurisdição processual avançada, cujo fundamento reside no acesso real, pleno e efetivo à justiça por parte dos cidadãos, de tal sorte que a ideia e a prática atuais da "cultura da sentença" impositiva sejam substituídas ou, pelo menos, minoradas, pela "cultura da pacificação" por meio do consenso. ${ }^{8}$

\section{ASPECTOS GERAIS SOBRE CONCILIAÇÃO E MEDIAÇÃO}

A doutrina favorável à institucionalização de mecanismos de resolução amigável dos litígios sustenta que, além de prevenir, reduzir ou encurtar o processo, a autocomposição possui uma "função pacificadora, muito superior à pacificação obtida pela sentença autoritativa do juiz", já que esta "deixará sempre uma das partes - e frequentemente ambas - descontente com o resultado do processo". 9

No tocante aos institutos sob relação, é imperioso destacar o fato de que estes, a despeito de denotarem elementos comuns, ostentam diferenças bem significativas, inclusive sob o prisma da finalidade específica, do método e dos vínculos entre as partes litigantes. ${ }^{10}$

É verdade que ambos são procedimentos de autocomposição de conflitos, com o objetivo geral de pacificação social das relações conflitivas. Esclareça-se que os meios "não-adversariais", espécies do gênero de resolução de conflitos, são técnicas exorbitantes do "modelo contencioso, caracterizado pela competição e pelo antagonismo", que buscam "uma forma de resolver o conflito por um modelo coexistencial, de cunho colaborativo". ${ }^{11}$

Pode-se expressar, especificamente, que a conciliação é um método de composição consensual de controvérsias, realizado pelas próprias partes sob 
litígio, por intermédio de um terceiro, imparcial e "neutro", que participa do procedimento como agente incentivador, facilitador e auxiliar das partes com intuito de que elas alcancem um acordo. ${ }^{12} \mathrm{Na}$ conciliação, o agente imparcial deve expressar "opinião sobre a solução justa para o conflito e propõe os termos do acordo" 13 . Em outras palavras, a autoridade conciliadora "deve facilitar o diálogo entre as partes, ressaltando as vantagens da conciliação, incentivar as partes a proporem soluções e sugerir formas de solução para o conflito entre as partes" ${ }^{14}$ Efetivamente, o conciliador detém uma condição de "parte ativa, emitindo opiniões, aconselhando as partes, indicando sua visão a respeito da futura decisão judicial". ${ }^{15}$

Expresso por outro modo, o agente conciliador "pode apresentar sugestões apenas na exata medida da objetividade do conflito que está tratando, mas cumpre-lhe estimular as partes a elaborar soluções próprias e integrativas”. Não se confunda, porém, o ato de estimular com a coação psicológica, pois "o conciliador não está autorizado a forçar ou pressionar as partes para que realizem acordo algum, porque essas práticas comprometem a idoneidade do próprio meio". ${ }^{16} \mathrm{E}$ isso é assim pelo fato de que a participação do conciliador "não pode sobrepor-se à vontade das partes, o que não só comprometeria a idoneidade do método, mas também poderia provocar diversos malefícios ao sistema de Justiça” ${ }^{17}$ Em suma, é certo pontuar que o agente conciliador detém condição mais ativa, tanto é que pode indicar um modelo de autocomposição, isto é, "sugerir às partes os termos em que o acordo poderia ser realizado, dialogando abertamente com elas a este respeito" ${ }^{18}$ Pontue-se, ademais, que, em geral, essa atividade de autocomposição é "desenvolvida pelo próprio juiz ou por pessoa que faz parte ou é fiscalizado ou orientado pela estrutura judicial." ${ }^{19}[\mathrm{sic}]$

No tocante à tipologia do conflito, diz-se que a conciliação é o meio consensual apropriado à composição da litigiosidade objetiva, dado que a sua natureza é de menor profundidade e complexidade fáticas relativamente à mediação. ${ }^{20} \mathrm{Em}$ outras palavras, a conciliação é mais afeita à finalidade de resolver conflitos, em que as partes, regra geral, não mantêm vínculos em relação subjetiva continuada, mas solucionar a lide nos estritos termos das questões objetivas e imediatas oferecidas pelos envolvidos. ${ }^{21} \mathrm{E}$ é por isso que se afirma que o método da conciliação denota menor complexidade e exige um lapso menor para ser operacionalizado em relação a outros procedimentos consensuais de composição, pois, como já registrado, preponderam naquele os aspectos objetivos ${ }^{22}$, isto é, questões exclusivamente de direito material, consoante leciona Juan Carlos Vezzulla. ${ }^{23}$

Já no pertinente à mediação, é válido assinalar o fato de que também é meio de composição consensual de conflitos realizado pelas próprias partes, sob a coordenação do tertius imparcial. O mediador, entretanto, atua apenas como auxiliador ou facilitador da comunicação entre as partes, ajudando-as a compreender melhor a verdadeira controvérsia responsável pelo litígio. ${ }^{24} \mathrm{E}$ a razão disso é que "As pessoas que vivenciam a controvérsia são as responsáveis por sua administração e solução. O poder é das partes e não do mediador”. ${ }^{25} \mathrm{Em}$ 
face disso - solução pelas próprias partes - é que se enquadra a mediação como espécie de resolução de conflitos de interesses pelo método autocompositivo.

A mediação efetiva-se, com efeito, por meio de relação dialógica entre as partes, que, de forma amigável e aberta, devem buscar o melhor caminho a ser seguido para compor a quizília. Amigável porque nenhuma das partes pode obrigar a outra ou ser obrigada por ela a dialogar. Afinal, mediação é diálogo. Juan Carlos Vezzulla consigna a mediação como instrumento de "resolução de conflitos não adversarial, que, sem imposições de sentenças ou de laudos e, com um profissional devidamente formado, auxilia as partes a acharem seus verdadeiros interesses e a preservá-los num acordo criativo onde as duas partes ganham" ${ }^{26}$

Lília Maia de Morais Sales, em sua tese de doutoramento, por sua vez, conceitua mediação, nos seguintes termos:

Mediação procede do latim mediare, que significa mediar, dividir ao meio ou intervir. Estes termos expressam o entendimento do vocábulo mediação, que se revela um procedimento pacífico de solução de conflitos. A mediação apresenta-se como uma forma amigável e colaborativa de solução de controvérsias que buscam a melhor solução pelas partes. É um procedimento em que e através do qual uma terceira pessoa age no sentido de encorajar e facilitar a resolução de uma disputa, evitando antagonismo, porém sem prescrever a solução. As partes são as responsáveis pela decisão que atribuirá fim ao conflito. ${ }^{27}$

A finalidade específica da mediação é solucionar com a maior abrangência e profundidade possiveis conflitos entre os litigantes, de tal forma que tanto conflito imediato, isto é, a questão jurídica propriamente dita, como a "lide sociológica", na expressão de Francesco Carnelluti, sejam integralmente solucionadas, inclusive "com plena aceitação do resultado pelos envolvidos", já que a decisão advém de mútuo, livre e voluntário acordo efetivado por eles. ${ }^{28}$

$\mathrm{Na}$ verdade, considerando o fato de que o conflito público e ostensivo representa muitas vezes indicação rudimentar do problema, pois, regra geral, são litígios que soem acontecer entre pessoas que travam relações de natureza dilatada no tempo e no espaço, isto é, continuadas, a ideia da mediação é perscrutar todo o plexo de elementos da questão (sociológicos, psicológicos), a fim de que haja real e integral composição da lide entre os contendedores, com superação dos problemas e também com enorme expectativa de formulação de paz duradoura entre eles. ${ }^{29}$ Numa frase, aos conflitos nos quais preponderam os aspectos pessoais, mas não necessariamente afetivos ${ }^{30}$, deve ser aplicada a mediação, pois esse método privilegia a pacificação social em sentido amplo, e não somente a efetivação de um acordo formal, pontual e precário entre as partes litigantes. ${ }^{31}$ Nessa linha é a ponderação de Ricardo Santos, quando explica que o escopo da mediação é mais amplo do que o da conciliação, pois a finalidade é a "pacificação restauradora das relações conflituosas, e não das circunstâncias pontuais, motivadoras do conflito". ${ }^{32}$ 
Ainda a respeito da diferença de natureza das questões relacionadas às duas figuras jurídicas em estudo, releva evidenciar, a título de matérias e casos afeitos a cada um desses institutos, a ponderação de Adolfo Braga Neto, para quem o método da conciliação

[...] não envolve desdobramentos de longos anos de relacionamentos e sim um fato ocorrido que fez nascer uma breve ou momentânea inter-relação, como é o caso de um abalroamento de veículos, uma relação de consumo, onde as partes não convivem, mas somente necessitam de um terceiro que as ajude a refletir sobre qual seria a melhor solução para a controvérsia e se valeria a pena enfrentar a outra parte de forma litigiosa. Diferente da mediação, onde o que está em jogo constituem-se meses, anos ou décadas de relacionamento, que demanda um conhecimento mais aprofundado do terceiro para que se possa auxiliá-lo nas questões controversas, pois quanto menor sua interferência, partindo-se do pressuposto de que sua intervenção é modificadora da relação, exige mais tempo para se alcançar a resolução mesmo por que ele buscará levar as partes a pensar nos seus interesses, necessidades, e sobretudo no futuro e não fincá-las no conflito e com isso no passado. ${ }^{33}$

Assim sendo, pode-se concluir que, enquanto a conciliação visa a reparar topicamente os danos ocasionados pela(s) parte(s), a mediação exprime três funções principais: repara os danos (passado), restaura o relacionamento (presente) e previne (futuro) a incidência de mais conflitos, sendo, por isso, um meio consensual mais completo para lidar com a litigiosidade de "relações qualificadas pela existência de múltiplos vínculos, que por serem continuadas, não devem ser interrompidas após a resolução de uma controvérsia”. ${ }^{34}$

Ainda no tocante às considerações gerais sobre os institutos da conciliação e da mediação, importante também tocar, ainda que rapidamente, sobre três de seus princípios informativos, mas tão-somente na medida do estritamente necessário para a questão central deste artigo.

Não obstante os princípios informativos de ambos os institutos variarem de país para país, é possível relatar que os seguintes são comumente aceitos para estruturar tais meios de composição não "adversariais": autonomia das partes; não competitividade; poder decisório das partes; mediador (terceiro imparcial); informalismo do procedimento; confidencialidade. ${ }^{35}$ Neste trabalho, somente serão abordados os três primeiros.

No tocante à autonomia das partes, esta significa que os sujeitos participantes da conciliação/mediação devem estar livres e conscientes para optarem por uma solução consensual. Com efeito, a liberdade das partes têm duas faces: "a liberdade para optar pela mediação [inclua-se, também, pela conciliação] como meio de solução de conflitos e a liberdade para decidir e resolver o conflito no processo de mediação" ${ }^{36}$ Em suma, ninguém pode ser forçado a submeter o seu conflito a procedimentos de resolução consensual, sob pena de violação do princípio da autonomia e voluntariedade que orienta os métodos não-adversariais. ${ }^{37}$ 
Já o princípio da não competitividade diz respeito à ausência de conflituosidade do procedimento de conciliação/mediação, na medida em que as partes não devem se orientar no sentido de impor uma derrota à outra, mas de molde que ambas sejam beneficiadas a um só tempo pelo acordo firmado por elas. E a razão disso é que, nos procedimentos de autocomposição, não existe a lógica do "tudo ou nada", isto é, do "perde-se ou ganha-se". O fundamento é, contrariamente, o da solução acordada amigavelmente, na qual somente existem ganhadores, nunca derrotados, pois as partes deixam de ser litigantes tradicionais - adversários - e passam a ostentar a condição de agentes mediados responsáveis pela formatação do acordo. Com efeito, aduz Boaventura de Sousa Santos, a "estrutura da mediação [inclua-se, também, conciliação] é topográfica de um espaço de mútua cedência e de ganho recíproco". ${ }^{38}$

Nesse sentido, do ponto de vista do devido processo legal, pondera Petronio Calmon, a "Ampla defesa nos mecanismos para obtenção da autocomposição é participação, muito mais do que apresentação de provas, argumentos e recursos". 39 Afinal, de acordo com Ricardo Santos, em observação feita para mediação, mas legitimamente extensível a outros métodos consensuais, "as partes conflitantes [...], por meio de um trabalho conjunto e pautado no respeito mútuo, no diálogo e na realização de concessões parciais ou totais" podem descobrir, "dentre as soluções cabíveis para o conflito, aquela que melhor se adéqua ao caso concreto" ${ }^{40}$

Enfim, o princípio do poder de decisão expressa a ideia de que tão-somente as partes têm a faculdade de compor o litígio, por meio de um acordo no qual predominam a liberdade e a autonomia decisórias dos envolvidos, pois serão eles os diretamente afetados pela composição. Cabe transcrever, a respeito de tal princípio, a observação de Lília Maia Morais Sales, que, apesar de direcionada para a mediação, adequa-se também à técnica da conciliação. Confira-se:

Mediação não é um processo impositivo e o mediador não tem poder de decisão. As partes é que decidirão todos os aspectos do problema, sem intervenção do mediador, no sentido de induzir as respostas ou as decisões, mantendo a autonomia e controle das decisões relacionadas ao conflito. $\mathrm{O}$ mediador facilita a comunicação, estimula o diálogo, auxilia na resolução dos conflitos, mas não os decide. ${ }^{41}$

Passa-se, após essas considerações, à segunda parte do trabalho, na qual serão abordados os pontos referentes à conciliação e à mediação à luz de seus fundamentos democráticos e constitucionais.

\section{JURISDIÇÃO PROCESSUAL DEMOCRÁTICA: FUNDAMENTOS}

A democracia de há muito deixou de ser uma simples forma de governo e passou a se haver como um valor universal. Tal ideia foi expressamente recepcionada pela Constituição vigente, na medida em que elevou a democracia como um dos fundamentos do Estado de Direito brasileiro. O Texto constitucional, não 
bastasse isso, ainda especificou que a soberania popular, núcleo duro da ideia de democracia, será exercida por meio de representantes eleitos ou diretamente pelos cidadãos. Como instrumentos de democracia direta, a Lei Suprema previu, entre outros, o plebiscito, o referendo e a iniciativa popular.

Não é demais lembrar o fato de que a participação ativa dos cidadãos é peça tão elementar do sistema democrático que um dos mais importantes teóricos da democracia moderna, Jean-Jacques Rousseau, afirmou que a soberania popular é inalienável e indivisível. ${ }^{42}$

No plano jurídico-processual, o Documento Constitucional trouxe duas formas de participação direta dos cidadãos na administração da Justiça. Uma delas na condição de jurado, no tribunal popular do júri³ ${ }^{43}$ e a outra como juiz de paz. ${ }^{44}$ Com efeito, tem-se aí uma deferência clara ao cidadão por parte do legislador ordinário, que, diferentemente de visões elitistas e preconceituosas, visualizou as pessoas comuns como capazes de participar ativamente da interpretação e aplicação das normas jurídicas e do direito. Na verdade, é possível extrair da Constituição a ideia de que o cidadão, além de titular exclusivo da soberania, pode atuar diretamente nas decisões fundamentais para a coletividade. ${ }^{45}$

No tocante aos meios alternativos de composição de controvérsias, é lícito asseverar que o fundamento a reger a conciliação e a mediação é, igualmente, a democracia. Vale dizer, tais institutos nada mais são do que formas de concretizar a participação cidadã dos próprios litigantes na administração da Justiça. ${ }^{46}$ Nas palavras de Ada Pelllegrini Grinover, a administração da Justiça configura, a um só tempo, "instrumento de garantia e instrumento de controle, configurando meio de intervenção popular direta pelos canais institucionalizados de conciliação e mediação". ${ }^{47}$ Na mesma ideação e com verbalização diferente, referida autora expressa que "a intervenção de leigos na função conciliatória também se coloca no âmbito da participação popular na administração da justiça" ${ }^{48}$ Efetivamente, é uma maneira de descentralizar a jurisdição processual da esfera quase exclusiva dos juízes togados para os cidadãos, numa real distribuição de poder decisório processual para os litigantes, tornando o processo judicial um meio de participação democrática. ${ }^{49}$

De fato, os meios alternativos à jurisdição clássica, especificamente a conciliação e a mediação, ao elevarem os litigantes a agentes principais da composição dos conflitos, representam uma inflexão na lógica tradicional de julgamentos impositivos por parte de um juiz togado, situando no âmbito judicial as partes na condição de operadores diretos do processo de resolução das controvérsias, aumentando-lhes, com efeito, a responsabilidade política e social como cidadãos. Realmente, os meios de resolução compositiva de conflitos traz a possibilidade de incluir os cidadãos como protagonistas judiciais, convertendo-os de agentes processuais meramente passivos em operadores processuais ativos, dado que as partes passam diretamente a decidir as quizílias nas quais se encontram envolvidas, bem como a controlar o exercício da atividade jurisdicional, já que detêm a faculdade de encerrar ou não a controvérsia, excluindo-a da esfera decisória de poder dos magistrados togados. 
Outro aspecto da autocomposição de litígios que reforça a natureza democrática da conciliação e da mediação é o fato de tais procedimentos respeitarem a autonomia da vontade dos cidadãos, haja vista que as partes litigantes "nunca são obrigadas a celebrar qualquer tipo de acordo e não devem ser de qualquer forma constrangidas a celebrar acordo que não se coaduna com sua refletida vontade" ${ }^{50}$ Indubitavelmente, a autonomia é um dos elementos centrais da cidadania civil e política, na medida em que reconhece a pessoa como agente livre e consciente para decidir, do ponto de vista de seus valores, interesses e bens, o que melhor lhe aprouver. ${ }^{51}$

Advirta-se, ainda, para a ideia de que a autonomia é uma noção diametralmente oposta à de "menoridade", que, na semântica kantiana, é a incapacidade do indivíduo de "se servir do entendimento sem a orientação de outrem" ${ }^{52}$. Ora, os métodos conciliadores e mediadores trazem intrinsecamente a possibilidade, no campo da idealidade, do exercício pleno da autonomia da vontade, na medida em que permitem às partes interessadas deliberar com ampla liberdade acerca do conteúdo, condições e termos da decisão final do litígio. ${ }^{53}$ Tem-se, com efeito, no microssistema processual, uma das manifestações da autonomia da vontade, na medida em que as partes formulam as própria regras para compor as desavenças por meio da cooperação e confiança recíprocas. Assim, as partes litigantes são, a um só tempo, os autores e os destinatários de suas leis, de tal sorte que o acordo firmado com base nelas cria direitos e obrigações para as respectivas partes, pois, a priori, foi realizado com respeito integral e efetivo ao princípio da autonomia da vontade. ${ }^{54}$

E o exercício da autonomia das partes concretiza o "fundamento político da jurisdição por permitir a participação popular na administração da justiça". Efetivamente, observa Érica Barbosa e Silva ${ }^{55}$, a concretização dessa autonomia ocorre pelo "enaltecimento das responsabilidades pessoais sobre a geração do conflito e sobre sua respectiva resolução", favorecendo, tal perspectiva, o "senso de colaboração entre as partes" e o "sentido pedagógico" da participação direta na resolução da questão, "pois as pessoas, com experiência, deverão aprender a lidar com o conflito e buscar, por si próprias, sua adequada superação, alternando possibilidades que seguem ao lado do paternalismo estatal na resolução de conflitos".

É lícito fincar, portanto, a ideia segundo a qual os meios consensuais de resolução de controvérsias têm por base o princípio da autonomia da vontade ${ }^{56}$, que é um dos elementos essenciais da democracia, num regime político no qual os cidadãos são tratados e reconhecidos como pessoas livres e iguais em direitos e obrigações pelo Estado.

É força convir, para finalizar, que os meios dialógicos de resolubilidade conflitiva possuem a prerrogativa de impregnar marcas profundas de participação cidadã na administração da justiça, de tal forma ser possível sustentar que o aperfeiçoamento e a criação de instrumentos de superação compositiva de controvérsias podem transformar a jurisdição processual tradicional, de natureza competitiva e impositiva, em uma genuína jurisdição processual democrática, isto é, de natureza participativa, colaborativa e consensual. ${ }^{57}$ 


\section{AUDIÊNCIA DE CONCILIAÇÃO E DE MEDIAÇÃO NO NOVO CÓDI- GO DE PROCESSO CIVIL (NCPC): INOVAÇÕES E ACESSO À JUSTIÇA}

Nos tópicos anteriores, abordaram-se os fundamentos teóricos relativos ao tema em estudo. Neste tópico, discutem-se os reflexos, de ordem prática ou procedimental, concernentes às inovações introduzidas no sistema processual, com o advento da audiência de conciliação e de mediação pelo NCPC. Também será objeto de análise a relação das referidas alterações legislativas com o conceito contemporâneo de jurisdição e de acesso á justiça.

3.1 Considerações gerais de cunho comparativo entre a audiência preliminar (art. 331, CPC/73) e a audiência de conciliação ou de mediação (art. 334, NCPC)

A Lei 8952/94, ao modificar a redação do art. $331,^{58}$ introduziu no Código de Processo Civil (CPC) brasileiro a audiência preliminar.

O texto vigente do art. 331 do $\mathrm{CPC} / 73$, conforme redação dada pela Lei 10.444/02, ${ }^{59}$ prevê, em síntese, a tentativa de conciliação, e, não sendo esta obtida, estatui também a fixação dos pontos controvertidos, a decisão sobre as questões processuais pendentes e a determinação das provas a serem produzidas.

Efetivamente, portanto, a conciliação se constitui em uma das etapas ou fases do complexo ato processual intitulado audiência preliminar.

A audiência de conciliação e de mediação, de que trata o art. 334 do NCPC, difere bastante, em conteúdo e forma, da audiência prevista no citado art. 331 do $\mathrm{CPC} / 73 .{ }^{60}$

Com vistas a conferir uma visão panorâmica, somente para fins de introdução ao estudo que será mais à frente desenvolvido, indicam-se a seguir as principais alterações entre os referidos modelos. Os comentários serão desenvolvidos, tomando-se como base a audiência de conciliação e de mediação.

Quanto ao momento de realização, perceba-se que a audiência preliminar ocorre depois do exercício da defesa pelo réu, enquanto a audiência de conciliação ou de mediação a antecede.

No que diz respeito às atividades a serem realizadas, a primeira evidência a saltar aos olhos é que a audiência do Novo Código de Processo Civil (NCPC) ganha em especialidade, na medida em que é dedicada à tentativa de autocomposição, enquanto, na audiência preliminar, esta é uma importante função, porém não exclusiva.

E como decorrência dessa, por assim dizer, especialização funcional da audiência de conciliação e de mediação, surge uma gama de outras distinções ou peculiaridades.

Nesse sentido, é prevista, necessariamente, a participação de conciliadores ou mediadores (onde houver), o que não se verifica na audiência preliminar. 
É possível a realização de mais de uma sessão, desde que em um intervalo máximo de dois meses a contar da primeira. Há de ser necessária a designação de sessões adicionais, sempre com vistas a obter a composição consensual. ${ }^{61}$

As partes podem, ainda, com a condição de o fazerem expressamente, manifestar desinteresse relativo à composição, evitando a realização da audiência. O NCPC é claro ao exigir a manifestação de ambas as partes nesse sentido. ${ }^{62}$

Outras novidades consistem na fixação de um intervalo mínimo de 20 (vinte) minutos entre cada audiência de conciliação e de mediação, bem como na possibilidade de sua realização por meio eletrônico.

O autor é intimado para a audiência na pessoa de seu advogado. O réu, por sua vez, é citado. A parte pode nomear representante para comparecer à audiência, por intermédio de procuração específica que contenha poderes para negociar e transigir.

É prevista uma multa de até $2 \%$ (dois por cento) do valor da causa ou da vantagem econômica almejada em caso de não comparecimento injustificado das partes à audiência. $\mathrm{O}$ valor da multa é destinado à União ou ao Estado-membro.

Em linhas gerais, essas são as principais modificações surgidas com o advento da audiência de conciliação e de mediação do NCPC, em comparação à audiência preliminar do CPC/73.

3.2 Dos requisitos básicos para a designação da audiência de conciliação e de mediação

A audiência será designada pelo juiz se a petição inicial preencher os requisitos essenciais e se não for o caso de improcedência liminar do pedido. $\mathrm{O}$ NCPC prevê, entretanto, hipóteses em que a audiência não será realizada. ${ }^{63}$

Como já visto, uma das situações ocorrerá quando ambas as partes, de forma expressa, aduzirem que não têm interesse na composição $\left(\S 4^{\circ}, \mathrm{I}, 334\right)$.

O NCPC estabelece, inclusive, o modus pelo qual autor e réu devem manifestar seu desinteresse. $O$ autor, já na petição inicial, e o réu, por petição com 10 (dez) dias de antecedência da data da audiência $\left(\S 5^{\circ}, 334\right)$.

Assim, quando ambas as partes declinarem da composição, resta claro que a audiência não deve mesmo se realizar.

Questão interessante de ordem prática pode surgir quando só uma das partes manifestar, nos devidos termos legais, desinteresse na tentativa de autocomposição, enquanto a outra manifestar seu interesse ou mesmo não expressar desinteresse, concordando, tacitamente, portanto, com a realização do ato.

Numa interpretação estritamente gramatical do referido $\S 4^{\circ}$, I, do art. 334 , e se ocorrentes os demais requisitos legais, a audiência deveria ocorrer. 
É possível argumentar que a obrigatoriedade de comparecimento também se alinha com a política legislativa e social em prol do incentivo à efetivação dos meios equivalentes de jurisdição.

Na Lei dos Juizados Especiais Cíveis e Criminais (Lei 9.099/95), há consequência processual para o não comparecimento do demandado à sessão de conciliação. De fato, reputar-se-ão verdadeiros os fatos alegados na peça inicial, salvo convicção em contrário do juiz, devendo ser proferida sentença de logo, tudo conforme os arts. 20 e 23 da referida Lei.

Evidentemente, há particularidades do sistema de tutela dos interesses e direitos relativos ao JECC, mas o fato é que o exemplo é válido para demonstrar que o ordenamento jurídico já contempla legislação que privilegia audiência com vistas a obter a autocomposição em juízo, estabelecendo consequências processuais pelo não comparecimento à mesma.

Além do mais, o interesse de uma das partes na autocomposição, mesmo que embrionário, somado ao cenário positivo concebido pelo NCPC quanto à estruturação e profissionalização do ato e dos auxiliares nele envolvidos, parecem justificar, em alguma medida, o investimento na realização da audiência, em face da razoável expectativa de um desfecho alinhado aos propósitos do ato processual em destaque.

De outra parte, não se pode olvidar que um dos princípios norteadores da conciliação e da mediação é o da autonomia da vontade das partes. Nesse sentido, não parece nada razoável compelir alguém a participar de conciliação ou mediação que não deseja.

Uma solução para tais casos, que se refiram especificamente à mediação, talvez seja a de se sustentar a realização da primeira audiência apenas nas hipóteses em que houver eleição contratual prévia do instituto (da mediação).

Essa alternativa estaria em consonância, inclusive, com o art. $2^{\circ}, \S 1^{\circ}$ da recentíssima Lei 13.140/2015, ao determinar que, nos casos nos quais existir previsão contratual de cláusula de mediação, as partes deverão comparecer à primeira reunião.

Com relação, no entanto, aos casos de conciliação, e mesmo àqueles de mediação em que não foi prevista cláusula em contrato sobre sua observância, não há como obrigar a parte a uma audiência dessa natureza contra a sua vontade.

Vale ressaltar, ainda, e em reforço à ideia acima defendida, de que há de se necessariamente garantir e orientar a mediação (e a conciliação) pelo principio da voluntariedade, pois o $\S 2^{\circ}$ da citada Lei sobre a mediação prevê que "Ninguém será obrigado a permanecer em procedimento de mediação" $\left(\S \S 1^{\circ}\right.$ e $2^{\circ}$ do $\left.\operatorname{art} .2^{\circ}\right)$.

A audiência também não será realizada nas hipóteses em que o interesse ou o direito não admitir autocomposição (\$4, II, 334, NCPC). 
$\mathrm{O} \S 3^{\circ}$ do art. 331 do $\mathrm{CPC} / 73$ refere-se, quanto ao ponto, aos casos em que o direito em litígio não admite transação, para autorizar o juiz a sanear logo o processo e ordenar a produção da prova.

Comparativamente, o elastério conferido pelo texto do NCPC possibilita autocomposições que vão além dos direitos patrimoniais.

Eduardo Cambi explica com propriedade: "[...] o art. 334, § 4 , do NCPC utilizou expressão mais ampla que o art. 331, caput, do CPC-73 ('e versar sobre direitos que admitam transação'). Com isso, ampliou o objeto de possíveis conciliações ou mediações, pois o art. 841 do Código Civil possui redação restritiva, in verbis: 'Só quanto a direitos patrimoniais de caráter privado se permite a transação'). Assim, não apenas os direitos disponíveis podem ser objeto de autocomposição. Mesmo direitos indisponíveis podem ser resolvidos pela conciliação ou mediação (v.g., os alimentos devidos por parentes são indisponíveis porque irrenunciáveis), mas o valor, a forma e o prazo podem ser objeto de transação; o réu de investigação de paternidade pode reconhecer juridicamente o pedido". ${ }^{64}$

\subsection{Da atuação necessária do conciliador ou do mediador}

O NCPC, pode-se dizer, investiu na busca de resolução consensual dos conflitos. Para tanto, definiu as atribuições de conciliadores e mediadores, estabeleceu a necessidade dos tribunais criarem centros judiciários de solução consensual de conflitos, positivou os princípios informativos da conciliação e da mediação, além de tantas outras regulações em torno da matéria. ${ }^{65}$

Previu, inclusive, que "a conciliação, a mediação e outros métodos de solução consensual de conflitos deverão ser estimulados por juízes, advogados, defensores públicos e membros do Ministério Público, inclusive no curso do processo judicial" (\$ 3, art. 30, NCPC).

Estatuto da Advocacia já dispunha o fato de que é dever do advogado estimular a conciliação entre os litigantes, buscando prevenir a instauração de litígios (art. 2, § único da Lei 8.906/1994).

O referido texto do NCPC, portanto, não representa inovação, pelo contrário, consolida pertinentemente a matéria (assim como o Código faz com outros institutos e matérias), reforçando o ideal em prol da efetivação dos meios equivalentes de jurisdição.

Ressalte-se que o NCPC também estimula a autocomposição em atos processuais posteriores à audiência de conciliação ou mediação. Isso pode ocorrer nas hipóteses em que não se obteve acordo na própria audiência referida, ou mesmo quando a transação foi apenas parcial, por exemplo.

Com efeito, o juiz tentará a conciliação quando instalada a audiência de instrução e julgamento (art. 359, NCPC). É incumbência do relator do recurso homologar autocomposição das partes (art. 932, I, NCPC). E, aliás, 
incumbe ao juiz promover, a qualquer tempo, a autocomposição (art. 139, $\mathrm{V}, \mathrm{NCPC})$.

Diante de todo esse contexto, compreende-se o sentido do texto de que trata este tópico, qual seja, "o conciliador ou mediador, onde houver, atuará necessariamente na audiência de conciliação ou de mediação, observando o disposto neste Código, bem como as disposições da lei de organização judiciária” (§ 1º art. 334, NCPC).

Realmente, não faria sentido investir na estruturação de todo um modelo direcionado à efetivação dos meios equivalentes de jurisdição se não constasse a previsão, também, de que a participação dos conciliadores e mediadores seria necessária, pelo menos onde houvesse tais auxiliares.

Vale consignar a noção de que o NCPC, ao regular o procedimento atinente, no caso, à mediação e conciliação em juízo, não exclui outras formas extrajudiciais desses meios equivalentes de resolução de conflitos, vinculadas a órgãos institucionais ou realizadas por profissionais independentes, cuja regulação depende de lei própria (art. 175 do NCPC).

3.4 A previsão de prazos mínimos de antecedência para a designação de data para a audiência e para a citação do réu, bem como de intervalo mínimo entre as audiências

O legislador resolveu estabelecer prazos mínimos que devem ser observados para a prática de importantes atos relacionados à audiência de conciliação e de mediação.

Assim, previu que a audiência de conciliação ou de mediação deverá ser designada com antecedência de pelo menos 30 (trinta) dias, enquanto o réu deverá ser citado com antecedência mínima de 20 (vinte) dias, contados da data da audiência (caput, art. 334, NCPC).

Esses prazos justificam-se, respectivamente, tanto pela necessidade de ultimação dos atos atinentes à intimação e citação, quanto para propiciar ao réu um tempo mínimo entre a comunicação e a audiência, lembrando que o $\S 5^{\circ}$ do art. 334 estabelece que o réu deve apresentar eventual desinteresse na autocomposição com 10 (dez) dias de antecedência, contados da data da audiência.

A previsão de intervalo mínimo de 20 (vinte) minutos entre o início de uma audiência e o começo da seguinte visa a oportunizar sempre mais a negociação, o diálogo com vistas a obter a composição, buscando-se, em última análise, a efetividade dos meios equivalentes de jurisdição.

3.5 Da novidade da audiência por meio eletrônico e a sanção pelo não comparecimento à audiência

$\mathrm{Na}$ sistemática vigente, sob a égide do $\mathrm{CPC} / 73$, não é incomum as partes deixarem de comparecer à audiência preliminar. 
Os operadores do direito, pelo contrário, tendem a comparecer. Como visto anteriormente neste trabalho, caso não seja obtida a conciliação, o juiz deve, em continuidade à audiência, fixar os pontos controvertidos, decidir as questões processuais pendentes e determinar as provas a serem produzidas, o que, naturalmente, os atrai, dada a importância dos aludidos atos para o desfecho do processo.

O aspecto de ordem cultural influencia na adesão ou não das partes às audiências que visam à autocomposição, de que é exemplo expressivo a audiência preliminar.

O jurisdicionado e o próprio operador, no Brasil, ainda estão habituados e alimentam, em geral, uma visão litigiosa e judicial dos conflitos. Enquanto não houver uma mudança de mentalidade para prestigiar a cultura da pacificação, inclusive, levada a cabo por intermédio do fortalecimento dos meios equivalentes de jurisdição, essa dificuldade tende a persistir.

Esse movimento é gradual e depende de fatores diversos. Um deles, certamente, diz respeito ao agasalhamento dessa tendência de reforço da importância da conciliação, da mediação e da arbitragem no âmbito da legislação, o que de fato vem acontecendo, como no caso do NCPC.

Outro fator que desestimula a participação é a ausência de sanção pelo não comparecimento à convocação do juízo, pelo menos até que haja a sedimentação de uma nova cultura, tanto pelo jurisdicionado, quanto pelos operadores do direito. ${ }^{66}$

O legislador do NCPC posicionou-se expressamente nesse tocante. O $\$ 8$ do art. 334 prevê que o não comparecimento injustificado à audiência configura ato atentatório à dignidade da justiça, além de incorrer o faltoso em multa de até dois por cento do valor da causa ou "da vantagem econômica pretendida", a ser destinada à União ou ao Estado-membro, a depender se o processo tramita na Justiça Federal ou Estadual, respectivamente.

Veja-se que, evidentemente, não se pune o fato de não se transigir, mas o não comparecimento, sem justificativas - registre-se - à audiência.

O NCPC também previu a possibilidade de realização da audiência por meio eletrônico, nos termos da lei (§ $7^{\circ}$, art. 334). É outro elemento facilitador ou de incentivo à efetiva realização da audiência.

O meio eletrônico que melhor se coaduna com as características do ato é a videoconferência. Como se sabe, por essa tecnologia, são transmitidos som e imagem, com o que é minimizada a ausência física dos participantes, de modo a possibilitar razoável interação com vistas ao atingimento do objetivo central da audiência, que é a tentativa de composição consensual.

A vantagem de se permitir a realização da audiência por intermédio de meio eletrônico reside, sobretudo, na economia de tempo, em face da redução ou eliminação de deslocamentos por vezes onerosos para as partes. 
Outro fator que contribui para a efetiva ultimação da audiência reside na possibilidade de a parte ser representada na audiência. A procuração deve

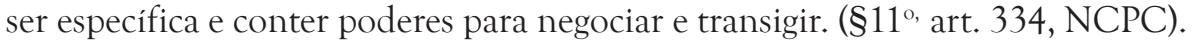

As partes, ou quem as represente, devem comparecer acompanhadas por seus advogados ou defensores públicos $\left(\S 9^{\circ}, 334\right.$, NCPC). Embora o texto não faça menção, o advogado pode funcionar também como representante da parte, desde que munido dos poderes há pouco referidos.

3.6 Inovações legislativas relativas à audiência de conciliação e de mediação do NCPC: avanço ou retrocesso à luz do conceito contemporâneo de jurisdição e de acesso à justiça

A análise sugerida por esse subtítulo, passa, evidentemente, pela delimitação dos conceitos contemporâneos de jurisdição e de acesso à justiça.

Rodolfo de Camargo Mancuso, em profundo estudo sobre a temática do acesso à justiça e temas correlatos, assevera que "O conceito contemporâneo de jurisdição deve hoje se descolar da necessária agregação à Justiça oficial, para, antes e superiormente, no contexto de uma democracia participativa, consentir uma vera jurisdição compartilhada com outros agentes, órgãos e instâncias capazes de prevenir ou resolver conflitos com justiça, em tempo razoável e sob uma boa equação custo-benefício". ${ }^{67}$

Com relação ao conceito contemporâneo de acesso à justiça, referido autor pondera que este "não pode mais ser tomado em modo generalizado ou até banalizado (num desvirtuamento da ideia de facilitação desse acesso): essa visão irrealista e ufanista é hoje impraticável, e engendra importantes externalidades negativas, que vão desde o desserviço à vera cidadania (que consiste, no primeiro momento, na busca da solução suasória dos conflitos), passando pelo estímulo à contenciosidade social, e, enfim, inflacionando a demanda por Justiça” ${ }^{68}$

Cogitar em jurisdição contemporânea, portanto, é aproximar-se do ideal de "jurisdição participativa”. É garantir que a solução dos conflitos seja realizada também por meios equivalentes, e não exclusivamente pela Justiça Estatal ou Oficial. Mais do que isso, é possibilitar a prevenção e a solução das controvérsias com justiça, em prazo razoável, e com o menor dispêndio de tempo, energia e custo possível.

O acesso à justiça, numa visão contemporânea, por sua vez, não admite mais uma simplória e superficial ligação do tema com o "abrir as portas" ao Judiciário, no sentido de sempre facilitar o ingresso em juízo. Muito menos deve ser relacionado com o reforço à ideia de incentivar a litigiosidade. Pelo contrário, significa privilegiar os meios auto e heterocompositivos na solução dos conflitos.

As alterações ou inovações trazidas pelo NCPC, no que diz respeito à audiência de conciliação e de mediação, aproximaram o sistema processual civil, em geral, dos conceitos contemporâneos de jurisdição e acesso à justiça. 
A propósito, perceba-se que o primeiro contato formal das partes no procedimento ordinário ocorre, atualmente, na audiência preliminar, após o exercício da defesa pelo réu. A audiência de conciliação e de mediação, ao contrário, e como já se disse, antecede a defesa. $\bigcirc$ ganho não está somente na abreviação do lapso para o primeiro contato com vistas à autocomposição. Como a defesa ainda não foi oferecida, as partes tendem a comparecer mais "desarmadas", num estado de ânimo possivelmente mais propício à autocomposição, sem contar que a solução será buscada necessariamente por profissionais habilitados e que o desiderato da audiência é voltado especificamente para alcançar a autocomposição, diferentemente do que ocorre com a audiência preliminar, na qual a conciliação é apenas fase ou etapa do ato.

Some-se a isso tudo, ainda, o fato de a legislação estipular um prazo mínimo de intervalo das audiências de conciliação e de mediação. Embora o prazo não seja elástico, garante uma pauta de audiências minimamente organizada com o propósito de propiciar tempo dedicado à autocomposição. Quer dizer, as inovações legislativas citadas apontam para maior especialização do ato processual e, sobretudo, para um dispêndio bem menor de energia (no sentido de se esperar outra fase processual) para a possível obtenção da solução da controvérsia por intermédio da autocomposição.

Outra demonstração da aderência das alterações legislativas em questão aos conceitos contemporâneos de jurisdição e acesso à justiça reside na previsão, anteriormente abordada, da possibilidade de realização da audiência por meio eletrônico, especialmente por videoconferência. Por vezes, o deslocamento para o ato, que pode até ser interestadual, representa custo significativo para as partes, e, mais do que isso, pode ensejar a própria impossibilidade de comparecimento, de modo a frustrar a autocomposição já em seu nascedouro.

São exemplos, ainda, de inovações que podem acarretar a resolução dos conflitos em prazo razoável, em alinhamento, portanto, à ideia de jurisdição contemporânea: a) a intimação do autor para a audiência por intermédio de seu advogado e b) a explicitação da possibilidade das partes nomearem representantes para comparecerem ao ato.

Vista sob outra perspectiva, a alínea “a” pode ser considerada um risco em potencial para o autor. É que, como ele não será pessoalmente intimado da audiência, é possível que tenha de arcar com as consequências do não comparecimento, sem que sequer tenha tido ciência prévia do ato processual. Esse risco deve ser realçado, na medida em que não está em jogo apenas a perda da possibilidade da autocomposição. Com efeito, uma das inovações do NCPC consiste justamente na fixação de uma multa de até 2\% (dois por cento) do valor da causa ou da vantagem econômica intencionada em caso de não comparecimento injustificado das partes à audiência.

Outro risco que pode ser citado relativamente à introdução da audiência de conciliação e mediação repousa na possibilidade de desequilíbrio da condição 
econômica e/ou social dos litigantes interferirem na condução e no resultado da autocomposição. Ou seja, a multiplicação da possibilidade da obtenção da autocomposição por esses meios, como reflexo das inovações, pode eventualmente representar também uma multiplicação de pacificações "sem justiça”, desequilibradas, obtidas por vícios de consentimento, com o que haveria um retrocesso, pelo menos de acordo com os conceitos contemporâneos de jurisdição e acesso à justiça.

Nesse sentido, Ada Pellegrini Grinover aduz que existem juristas que são contrários à conciliação, inclua-se também à mediação, "aduzindo a desigualdade jurídica ou organizacional entre os participantes, e as pressões delas derivadas, que não conseguiriam ser superadas por um terceiro facilitador, que não fosse o juiz". ${ }^{69}$

Petrônio Calmon adverte, igualmente, para a ideia de que "é preciso cuidar para que os sujeitos da autocomposição não ajam com liberdade apenas aparente. Por vezes falta a indispensável espontaneidade, característica essencial para a validade de qualquer negócio jurídico" ${ }^{70} \mathrm{O}$ autor explica que isso ocorre porque "A desigualdade cultural e econômica, dentre outros fatores, leva a que uma das partes ceda à vontade da outra sem perceber que não está obtendo a posição mais vantajosa possível". ${ }^{71}$

Há de se ponderar, porém, para o fato de que, nos moldes das próprias inovações, a audiência será conduzida por auxiliares da justiça habilitados (onde houver), cuja especialização tende a contribuir para minimizar referidas situações de desequilíbrio.

Ademais, impende ressaltar ser esse um risco subjacente não só à efetivação dos meios equivalentes de jurisdição, mas também à realização da solução adjudicada pelo Estado.

Assim, o risco efetivamente existe e merece toda a atenção dos operadores do direito, especialmente por parte dos juízes, mediadores e conciliadores. Não deve significar, porém, o desencorajamento do emprego da conciliação e da mediação, como meios fundamentais de resolução de conflitos voltados para o alcance do efetivo acesso à justiça.

\section{CONSIDERACุÕES FINAIS}

Não constitui novidade alguma a crise que acomete o Judiciário brasileiro. Uma crise de desconfiança nos serviços judiciais prestados à sociedade. Em grande medida, esta é produto da ineficiência da prestação jurisdicional pelo Estado-Juiz, decorrente de uma máquina judicial cara, lenta, pesada, burocrática e tradicionalmente elitizada.

O problema crítico é ocasionado pela inacessibilidade da maioria da população aos serviços prestados pela Justiça, já que não dispõe de recursos financeiros para arcar com as custas judiciais, honorários advocatícios e de sucumbência. Em 
face dessa crise, desenvolvem-se atualmente soluções alternativas ao modelo de administração da justiça clássica, tais como a mediação, conciliação, arbitragem e negociação. Este texto analisou, tão-somente, a conciliação e a mediação.

Infere-se do pesquisado que os institutos da mediação e da conciliação, do ponto de vista da ideia, têm o condão de auxiliar o acesso à justiça, por serem meios mais baratos, mais céleres e menos formais, bem como de proporcionar a participação popular na administração da justiça, pois são os próprios cidadãos litigantes os responsáveis diretos pela resolução definitiva do conflito.

Destaque-se, também, o fato de que os meios opcionais em estudo podem incentivar a formação de uma cultura da paz em substituição à cultura da competição, isto é, a óptica do outro como um adversário que deve ser derrotado a qualquer custo, pela perspectiva de estabelecer uma cultura dialógica, cooperativa e de respeito e tolerância.

É possível defender o ponto de vista de que a justiça consensual é um passo importantíssimo na estruturação e aperfeiçoamento de uma jurisdição processual democrática e participativa, na qual os cidadãos deixam de ser meros figurantes da relação processual e passam à condição de agentes responsáveis pela interpretação e aplicação direta da legislação e do direito na resolubilidade de conflitos.

Finalmente, as inovações legislativas respeitantes à audiência de conciliação e de mediação do NCPC, como se verificou, tendem, de uma forma geral, a compatibilizar o sistema processual civil brasileiro aos conceitos contemporâneos de jurisdição e acesso à justiça. Os riscos que surgem (ou são potencializados) com a maior utilização propiciada por tais inovações, embora mereçam toda a atenção (e tratamento adequado) dos operadores do direito, especialmente dos mediadores, conciliadores e juízes, não devem significar desencorajamento para que se efetivem a mediação e a conciliação na qualidade de meios para a realização do efetivo acesso à justiça e estruturação de uma jurisdição processual democrática.

\section{REFERÊNCIAS}

BRAGA NETO, Adolfo. Alguns aspectos relevantes sobre a mediação de conflitos. In: GRINOVER, Ada Pellegrini; WATANABE, Kazuo; LAGRASTE, Caetano (Coords.). Mediação e gerenciamento do processo: revolução na prestação jurisdicional. São Paulo: Atlas, 2008.

CALMON, Petronio. Fundamentos da mediação e da conciliação. Brasília: Gazeta Jurídica, 2013.

CAMBI, Eduardo. Audiência de conciliação e de mediação. In: WAMBIER, Teresa Arruda Alvim (et al.) (Coord.). Breves comentários ao Novo Código de Processo Civil. São Paulo: Revista dos Tribunais, 2015.

CARNEIRO, Athos Gusmão. Audiência de instrução e julgamento e audiências preliminares. 7 ed. Rio de Janeiro: Forense, 1995. 
DEMARCHI, Jualiana. Técnicas de conciliação e mediação. In: GRINOVER, Ada Pellegrini; WATANABE, Kazuo; LAGRASTE, Caetano (Coords.). Mediação e gerenciamento do processo: revolução na prestação jurisdicional. São Paulo: Atlas, 2008.

FABRETTI, Daniel. Conciliação e mediação em juízo. In: GRINOVER, Ada Pellegrini; WATANABE, Kazuo; LAGRASTE, Caetano (Coords.). Mediação e gerenciamento do processo: revolução na prestação jurisdicional. São Paulo: Atlas, 2008.

GRINOVER, Ada Pellegrini. Apresentação. In: CALMON, Petronio. Fundamentos da mediação e da conciliação. Brasília: Gazeta Jurídica. 2. ed., 2013.

. Os fundamentos da justiça conciliativa. In: GRINOVER, Ada Pellegrini; WATANABE, Kazuo; LAGRASTE, Caetano (Coords.). Mediação e gerenciamento do processo: revolução na prestação jurisdicional. São Paulo: Atlas, 2008.

KANT, Immanuel. Resposta à pergunta: que é o Iluminismo. In: KANT, Immanuel. A paz perpétua e outros opúsculos. Lisboa: Edições 70, 2009.

MANCUSO, Rodolfo de Camargo. Acesso à justiça: condicionantes legítimas e ilegítimas. São Paulo: Revista dos Tribunais, 2011.

MARTINS, Dayse Braga. A mediação no processo de democratização do Estado. In: SALES, Lílian Maia de Morais (Org.). Estudos sobre a mediação e arbitragem. Rio - São Paulo - Fortaleza: ABC Editora, 2003.

PINHO, Humberto Dalla Bernardina de. Prefácio. In: SANTOS, Ricardo Goretti. Manual de mediação de conflitos. Rio de Janeiro: Lumen Juris, 2012.

ROUSSEAU, Jean Jacques. O contrato social: princípios do direito político. São Paulo: Martins Fontes, 2003.

SADEK, Maria Tereza. Poder Judiciário: críticas e desafios. Ano Eleitoral: tempo para balanço. Cadernos Adenauer, Rio de Janeiro, Fundação Konrad Adenauer, a. III, n. 3, set., 2002.

SALES, Lília Maia de Morais. A mediação comunitária: instrumento de democratização da justiça. Pensar - Revista do Curso de Direito da Universidade de Fortaleza, vol. 7, n. 7, fev., 2002.

. Justiça e mediação de conflitos. Belo Horizonte: Del Rey, 2003.

SANTOS, Ricardo Goretti. Manual de mediação de conflitos. Rio de Janeiro: Lumen Juris, 2012, p. 60-79 e 312-314;

SILVA, Érica Barbosa e. Conciliação judicial. Brasília: Gazeta Jurídica, 2013.

VEZZULLA, Juan Carlos. Teoria e prática da mediação. 5. ed., Curitiba: Instituto de Mediação e Arbitragem do Brasil, 2001. 
1 SADEK, Maria Tereza. Poder Judiciário: críticas e desafios. Ano Eleitoral: tempo para balanço. Cadernos Adenauer, Rio de Janeiro: Fundação Konrad Adenauer, a. III, nº. 03, set., 2002, p. 131.

2 De acordo com Petrônio Calmon, a "inflação processual" é "a constatação de que a oferta [de serviços judiciais] não tem conseguido acompanhar a demanda" da população. CALMON, Petronio. Fundamentos da mediação e da conciliação. Brasília: Gazeta Jurídica. 2 ed., 2013, p. 134.

3 CALMON, Petronio. Fundamentos da mediação e da conciliação. Brasília: Gazeta Jurídica. 2 ed., 2013, p. 03-06, 23, 37 a 40, 134, 136, 141 e 151-152. GRINOVER, Ada Pellegrini. Os fundamentos da justiça conciliativa. In: GRINOVER, Ada Pellegrini; WATANABE, Kazuo; LAGRASTE, Caetano (Coords.). Mediação e gerenciamento do processo: revolução na prestação jurisdicional. São Paulo: Atlas, 2008, p. 01-05; SANTOS, Ricardo Goretti. Manual de mediação de conflitos. Rio de Janeiro: Lumen Juris, 2012, p. 60-79 e 312-314; SILVA, Érica Barbosa e. Conciliação judicial. Brasília: Gazeta Jurídica, 2013, p. 12;

4 PINHO, Humberto Dalla Bernardina de. Prefácio. In: SANTOS, Ricardo Goretti. Manual de mediação de conflitos. Rio de Janeiro: Lumen Juris, 2012, p. XVII; Ricardo Goretti. Manual de mediação de conflitos. Rio de Janeiro: Lumen Juris, 2012, p. XXI.

5 SILVA, Érica Barbosa e. Conciliação judicial. Brasília: Gazeta Jurídica, 2013, p.127-128, 328 e 344.

6 No presente trabalho, as expressões "meios alternativos", "meios consensuais", "meios equivalentes" "expedientes opcionais", dentre outras análogas, foram usadas como sinônimas, para significar modalidades de resolução de conflitos fora e além da solução adjudicada pelo Estado.

7 Evidente que é indefensável a ideia de que as fórmulas consensuais de resolução de conflitos sejam uma panaceia para os males do Judiciário, mas sim instrumentos que podem, em larga medida, minorar o déficit de uma prestação jurisdicional de qualidade, isto é, célere, efetiva, justa e democrática.

8 CALMON, Petronio. Fundamentos da mediação e da conciliação. Brasília: Gazeta Jurídica. 2 ed., 2013, p. 05 e 145; PINHO, Humberto Dalla Bernardina de. Prefácio. In: SANTOS, Ricardo Goretti. Manual de mediação de conflitos. Rio de Janeiro: Lumen Juris, 2012, p. XVII; SANTOS, Ricardo Goretti. Manual de mediação de conflitos. Rio de Janeiro: Lumen Juris, 2012, p. XXII.

9 GRINOVER, Ada Pellegrini. Apresentação. In: CALMON, Petronio. Fundamentos da mediação e da conciliação. Brasília: Gazeta Jurídica. 2 ed., 2013, p. IX.

10 CALMON, Petronio. Fundamentos da mediação e da conciliação. Brasília: Gazeta Jurídica. 2 ed., 2013, p. 99,103 a 106.

11 SILVA, Érica Barbosa e. Conciliação judicial. Brasília: Gazeta Jurídica, 2013, p. 169 e 177.

12 CALMON, Petronio. Fundamentos da mediação e da conciliação. Brasília: Gazeta Jurídica. 2 ed., 2013, p. 132, 133,

13 CALMON, Petronio. Fundamentos da mediação e da conciliação. Brasília: Gazeta Jurídica. 2 ed., 2013, p. 134.

14 DEMARCHI, Jualiana. Técnicas de conciliação e mediação. In: GRINOVER, Ada Pellegrini; WATANABE, Kazuo; LAGRASTE, Caetano (Coords.). Mediação e gerenciamento do processo: revolução na prestação jurisdicional. São Paulo: Atlas, 2008, p. 55.

15 CALMON, Petronio. Fundamentos da mediação e da conciliação. Brasília: Gazeta Jurídica. 2 ed., 2013, p. 140.

16 SILVA, Érica Barbosa e. Conciliação judicial. Brasília: Gazeta Jurídica, 2013, p. 173.

17 SILVA, Érica Barbosa e. Conciliação judicial. Brasília: Gazeta Jurídica, 2013, p. 173.

18 CALMON, Petronio. Fundamentos da mediação e da conciliação. Brasília: Gazeta Jurídica. 2 ed., 2013, p. 105.

19 CALMON, Petronio. Fundamentos da mediação e da conciliação. Brasilia: Gazeta Jurídica. 2 ed., 2013, p. 144.

20 DEMARCHI, Jualiana. Técnicas de conciliação e mediação. In: GRINOVER, Ada Pellegrini; WATANABE, Kazuo; LAGRASTE, Caetano (Coords.). Mediação e gerenciamento do processo: revolução na prestação jurisdicional. São Paulo: Atlas, 2008, p. 54-55.

21 CALMON, Petronio. Fundamentos da mediação e da conciliação. Brasilia: Gazeta Jurídica. 2 ed., 2013, p. 105.

22 DEMARCHI, Juliana. Técnicas de conciliação e mediação. In: GRINOVER, Ada Pellegrini; WATANABE, Kazuo; LAGRASTE, Caetano (Coords.). Mediação e gerenciamento do processo: revolução na prestação jurisdicional. São Paulo: Atlas, 2008, p. 54-55.

23 Apud BRAGA NETO, Adolfo. Alguns aspectos relevantes sobre a mediação de conflitos. In: GRINOVER, Ada Pellegrini; WATANABE, Kazuo; LAGRASTE, Caetano (Coords.). Mediação e gerenciamento do processo: revolução na prestação jurisdicional. São Paulo: Atlas, 2008, p. 65.

24 DEMARCHI, Juliana. Técnicas de conciliação e mediação. In: GRINOVER, Ada Pellegrini; WATANABE, Kazuo; LAGRASTE, Caetano (Coords.). Mediação e gerenciamento do processo: revolução na prestação jurisdicional. São Paulo: Atlas, 2008, p. 59. 
25 SALES, Lília Maia de Morais. A mediação comunitária: instrumento de democratização da justiça. Pensar - Revista do Curso de Direito da Universidade de Fortaleza, vol. 7, n. 7, fev., 2002, p. 175.

26 VEZZULLA, Juan Carlos. Teoria e prática da mediação. Santa Catarina: Instituto de Mediação e Arbitragem do Brasil, 5. ed., comentada e corrigida, 2001, p. 18.

27 SALES, Lília Maia de Morais. Justiça e mediação de conflitos, Belo Horizonte: Del Rey, 2003, p. 23-24.

28 CALMON, Petronio. Fundamentos da mediação e da conciliação. Brasília: Gazeta Jurídica. 2 ed., 2013 , p. 105 e 142.

29 CALMON, Petronio. Fundamentos da mediação e da conciliação. Brasília: Gazeta Jurídica. 2 ed., 2013 , p. 145.

30 Ricardo Santos adverte que a utilização do método da mediação não se restringe às relações conflituosas de natureza afetiva, "muito embora estas as que, com maior propriedade, exemplificam a continuidade à qual fazemos referência”. SANTOS, Ricardo Goretti. Manual de mediação de conflitos. Rio de Janeiro: Lumen Juris, 2012, p. 117.

31 DEMARCHI, Juliana. Técnicas de conciliação e mediação. In: GRINOVER, Ada Pellegrini; WATANABE, Kazuo; LAGRASTE, Caetano (Coords.). Mediação e gerenciamento do processo: revolução na prestação jurisdicional. São Paulo: Atlas, 2008, p. 59.

32 SANTOS, Ricardo Goretti. Manual de mediação de conflitos. Rio de Janeiro: Lumen Juris, 2012, p. 118.

33 BRAGA NETO, Adolfo. Alguns aspectos relevantes sobre a mediação de conflitos. In: GRINOVER, Ada Pellegrini; WATANABE, Kazuo; LAGRASTE, Caetano (Coords.). Mediação e gerenciamento do processo: revolução na prestação jurisdicional. São Paulo: Atlas, 2008, p.66. No mesmo sentido, ver: SANTOS, Ricardo Goretti. Manual de mediação de conflitos. Rio de Janeiro: Lumen Juris, 2012, p.116-120, 156-158. Ver, para uma abordagem mais pormenorizada das matérias e situações para as quais o método da mediação se faz mais indicado, SANTOS, Ricardo Goretti. Manual de mediação de conflitos. Rio de Janeiro: Lumen Juris, 2012, p. 156-158.

34 SANTOS, Ricardo Goretti. Manual de mediação de conflitos. Rio de Janeiro: Lumen Juris, 2012, p. 117. Para aprofundamento das características e diferenças entre conciliação e mediação, ver SILVA, Érica Barbosa e. Conciliação judicial. Brasília: Gazeta Jurídica, 2013, em especial, p. 133-149 e 169-193.

35 SALES, Lília Maia de Morais. Justiça e mediação de conflitos, Belo Horizonte: Del Rey, 2003, p. 44.

36 SALES, Lília Maia de Morais. Justiça e mediação de conflitos, Belo Horizonte: Del Rey, 2003, p. 45.

37 SANTOS, Ricardo Goretti. Manual de mediação de conflitos. Rio de Janeiro: Lumen Juris, 2012, p. 147-148.

38 Apud SALES, Lília Maia de Morais. Justiça e mediação de conflitos, Belo Horizonte: Del Rey, 2003 , p. 48.

39 CALMON, Petronio. Fundamentos da mediação e da conciliação. Brasília: Gazeta Jurídica. 2 ed., 2013 , p. 156.

40 SANTOS, Ricardo Goretti. Manual de mediação de conflitos. Rio de Janeiro: Lumen Juris, 2012 , p. 94.

41 SALES, Lília Maia de Morais. Justiça e mediação de conflitos, Belo Horizonte: Del Rey, 2003, p. 47.

42 ROUSSEAU, Jean Jacques. O contrato social - princípios do direito político, São Paulo: Martins Fontes, 2003, p. 33-34.

43 Constituição Federal de 1988: art. 5º, inciso XXXVIII.

44 Constituição Federal de 1988: art. 98, II.

45 MARTINS, Dayse Braga. A mediação no processo de democratização do Estado. In: SALES, Lílian Maia de Morais (Org.). Estudos sobre a mediação e arbitragem. Rio - São Paulo - Fortaleza: ABC Editora, 2003, p. 58.

46 GRINOVER, Ada Pellegrini. Os fundamentos da justiça conciliativa. In: GRINOVER, Ada Pellegrini; WATANABE, Kazuo; LAGRASTE, Caetano (Coords.). Mediação e gerenciamento do processo: revolução na prestação jurisdicional. São Paulo: Atlas, 2008, p. 05.

47 GRINOVER, Ada Pellegrini. Os fundamentos da justiça conciliativa. In: GRINOVER, Ada Pellegrini; WATANABE, Kazuo; LAGRASTE, Caetano (Coords.). Mediação e gerenciamento do processo: revolução na prestação jurisdicional. São Paulo: Atlas, 2008, p. 05.

48 GRINOVER, Ada Pellegrini. Os fundamentos da justiça conciliativa. In: GRINOVER, Ada Pellegrini; WATANABE, Kazuo; LAGRASTE, Caetano (Coords.). Mediação e gerenciamento do processo: revolução na prestação jurisdicional. São Paulo: Atlas, 2008, p. 05.

49 GRINOVER, Ada Pellegrini. Os fundamentos da justiça conciliativa. In: GRINOVER, Ada Pellegrini; WATANABE, Kazuo; LAGRASTE, Caetano (Coords.). Mediação e gerenciamento do processo: revolução na prestação jurisdicional. São Paulo: Atlas, 2008, p. 05.

50 DEMARCHI, Juliana. Técnicas de conciliação e mediação. In: GRINOVER, Ada Pellegrini; WATANABE, Kazuo; LAGRASTE, Caetano (Coords.). Mediação e gerenciamento do processo: revolução na prestação jurisdicional. São Paulo: Atlas, 2008, p. 61.

51 CALMON, Petronio. Fundamentos da mediação e da conciliação. Brasília: Gazeta Jurídica. 2 ed., 2013, p. 148, 154 e 157; SILVA, Érica Barbosa e. Conciliação judicial. Brasília: Gazeta Jurídica, 2013, p. 330, 332,334 e 336. 
52 KANT, Immanuel. Resposta à pergunta: que é o Iluminismo. In: KANT, Immanuel. A paz perpétua e outros opúsculos. Tradução de Artur Morão. Lisboa: Edições 70, 2009, p. 9.

53 BRAGA NETO, Adolfo. Alguns aspectos relevantes sobre a mediação de conflitos. In: GRINOVER, Ada Pellegrini; WATANABE, Kazuo; LAGRASTE, Caetano (Coords.). Mediação e gerenciamento do processo: revolução na prestação jurisdicional. São Paulo: Atlas, 2008, p. 65; CALMON, Petronio. Fundamentos da mediação e da conciliação. Brasília: Gazeta Jurídica. 2 ed., 2013, p. 30 , 47, 73, 132 e 142.; DEMARCHI, Juliana. Técnicas de conciliação e mediação. In: GRINOVER, Ada Pellegrini; WATANABE, Kazuo; LAGRASTE, Caetano (Coords.). Mediação e gerenciamento do processo: revolução na prestação jurisdicional. São Paulo: Atlas, 2008, p. 60; FABRETTI, Daniel. Conciliação e mediação em juízo. In: GRINOVER, Ada Pellegrini; WATANABE, Kazuo; LAGRASTE, Caetano (Coords.). Mediação e gerenciamento do processo: revolução na prestação jurisdicional. São Paulo: Atlas, 2008, p. 75.

54 SANTOS, Ricardo Goretti. Manual de mediação de conflitos. Rio de Janeiro: Lumen Juris, 2012, p. 147-148 e 176.

55 SILVA, Érica Barbosa e. Conciliação judicial. Brasília: Gazeta Jurídica, 2013, p. 189.

56 BRAGA NETO, Adolfo. Alguns aspectos relevantes sobre a mediação de conflitos. In: GRINOVER, Ada Pellegrini; WATANABE, Kazuo; LAGRASTE, Caetano (Coords.). Mediação e gerenciamento do processo: revolução na prestação jurisdicional. São Paulo: Atlas, 2008, p. 68.

57 CALMON, Petronio. Fundamentos da mediação e da conciliação. Brasília: Gazeta Jurídica. 2 ed., 2013, p. 145; SILVA, Érica Barbosa e. Conciliação judicial. Brasília: Gazeta Jurídica, 2013, p. 174.

58 A redação do art. 331, revogada pela Lei 8952, dispunha: "Se não se verificar nenhuma das hipóteses previstas nas seções precedentes, o juiz, ao declarar saneado o processo: I- decidirá sobre a realização de exame pericial, nomeando o perito e facultando às partes a indicação dos respectivos assistentes técnicos; II- designará audiência de instrução e julgamento, deferindo as provas que hão de produzir-se".

59 O texto vigente do art. 331 é o seguinte: "Se não ocorrer qualquer das hipóteses previstas nas seções precedentes, e versar a causa sobre direitos que admitam transação, o juiz designará audiência preliminar, a realizar-se no prazo de 30 (trinta) dias, para a qual serão as partes intimadas a comparecer, podendo fazer-se representar por procurador ou preposto, com poderes para transigir. $\S 1^{\mathrm{O}}$ Obtida a conciliação, será reduzida a termo e homologada por sentença. $\S 2^{\circ} \mathrm{Se}$, por qualquer motivo, não for obtida a conciliação, o juiz fixará os pontos controvertidos, decidirá as questões processuais pendentes e determinará as provas a serem produzidas, designando audiência de instrução e julgamento, se necessário. § 3 $\underline{0}$ Se o direito em litígio não admitir transação, ou se as circunstâncias da causa evidenciarem ser improvável sua obtenção, o juiz poderá, desde logo, sanear o processo e ordenar a produção da prova, nos termos do $\S 2$ $\underline{\mathrm{O}}$.

60 A ideia de concentrar maiores esforços no sentido de obter a resolução do conflito por meios autocompositivos, reservando uma audiência para tal fim, não representa alteração substancial no que diz respeito ao saneamento compartilhado. Isso porque o legislador previu no $\$ 3^{\circ} \mathrm{do}$ art. 357 do NCPC que "Se a causa apresentar complexidade em matéria de fato e de direito, deverá o juiz designar audiência para que o saneamento seja feito em cooperação com as partes, oportunidade em que o juiz, se for o caso, convidará as partes a integrar ou esclarecer suas alegações".

61 A jurisprudência já se posicionou, na vigência do art. 331 do $\mathrm{CPC} / 73$, pela desnecessidade de designação de nova audiência de conciliação em face do não comparecimento anterior de parte ao ato: "EMENTA. LOCAÇÃO. AC̣ÃO DE COBRANÇA ALEGAÇÃO DE QUITAC̣ÃO DA OBRIGAC̣ÃO. AUDIÊNCIA DE CONCILIAÇÃO. NÃO COMPÁRECIMENTO DA AUTORA. DESIGNAÇÃO DEE NOVA AUDIÊNCIA. DESNECESSIDADE (...). O não comparecimento da autora à audiência de conciliação não acarreta a obrigatoriedade de designação de nova audiência, uma vez que é faculdade da parte a transação. A ausência da parte corresponde à falta de interesse na composição. Recurso não provido. AP 00029063420108260156 , SP 0002906-34.2010.8.26.0156, Rel. José Malerbi, 35ª Câmara de Direito Privado, DJ 06/05/2013).

$62 \mathrm{Em}$ caso de litisconsórcio, o desinteresse na realização da audiência deve ser manifestado por todos os litisconsortes (\$ $7^{\circ}$, art. 334, NCPC).

63. A regra, portanto, é que, havendo os requisitos legais, a audiência deve ocorrer. OSTJ já decidiu, na vigência do atual art. 331 do $\mathrm{CPC} / 73$, que a não realização da audiência não importa em nulidade do processo quando as circunstâncias da causa evidenciarem ser improvável a obtenção da conciliação. Nesse sentido, ver AgRg no AREsp 552564, SP 2014/0180441-4, Rel. Min. Moura Ribiero, 3ª T., DJe 12/05/2015.

64 CAMBI, Eduardo. Audiência de conciliação e de mediação. In: WAMBIER, Teresa Arruda Alvim (et al.) (Coord.). Breves comentários ao Novo Código de Processo Civil. São Paulo: Revista dos Tribunais, 2015, p. 884-885.

65 Confira., principalmente, a Seção V, "Dos Conciliadores e Mediadores Judiciais, do Capítulo III, do Título IV do NCPC.

66 Athos Gusmão Carneiro, comentando o art. 331 do CPC/73, observa que as partes “(...) não estão obrigadas ao comparecimento, pois não está no CPC nenhuma sanctio iuris para os casos de inobservância da 
"determinação" contida nos arts. 331 (caso de audiência preliminar) e 447 (caso da audiência de instrução e julgamento". CARNEIRO, Athos Gusmão. Audiência de instrução e julgamento e audiências preliminares. 7 ed. Rio de Janeiro: Forense, 1995, p. 53.

67 MANCUSO, Rodolfo de Camargo. Acesso à justiça: condicionantes legítimas e ilegítimas. São Paulo: Revista dos Tribunais, 2011, p. 473.

68 MANCUSO, Rodolfo de Camargo. Acesso à justiça: condicionantes legítimas e ilegítimas. São Paulo: Revista dos Tribunais, 2011, p. 473.

69 GRINOVER, Ada Pellegrini. Apresentação. In: CALMON, Petronio. Fundamentos da mediação e da conciliação. Brasília: Gazeta Jurídica. 2 ed., 2013, p. XIV.

70 SANTOS, Ricardo Goretti. Manual de mediação de conflitos. Rio de Janeiro: Lumen Juris, 2012, p. 54.

71 SANTOS, Ricardo Goretti. Manual de mediação de conflitos. Rio de Janeiro: Lumen Juris, 2012, p. 54.

PROCEDURAL RULE AND DEMOCRACY: THE ADVENT OF CONCILIATION AND MEDIATION HEARING, THE REALIZATION OF EQUIVALENT PROCEDURAL MEANS AND THE ACCESS TO THE JUDICIAL SYSTEM

\begin{abstract}
Discuss the consensual means for resolution of conflicts, specifically the conciliation and the mediation. At first, it addresses the concerns whether these alternative means are compatible with democratic values, as they enable the litigants themselves as interpreters and law enforcers. Next, the Brazilian rules on conciliation and mediation, highlighting the main innovations introduced by the new Code of Civil Procedure (NCPC) are presented, especially in its concerns on hearing. Then, it is analyzed if these innovations mean an improvement in the access to the judicial system. Finally, it was reached the conclusion that the procedures of conciliation and mediation may provide direct participation of citizens in building justice and that the reform implemented by NCPC, regarding this matter, approaches the Brazilian civil procedural law to the contemporary concepts of democratic rule of law, and to the best practices on attaining solution for conflicts.
\end{abstract}

Keywords: Procedural law. Conciliation. Mediation. Democratic Procedure.

Submetido: 30 dez. 2015

Artigo convidado 